\title{
伝達行列の左分解表現に基づくモデルマッチング系の一構成法
}

\author{
加 瀬 渡*
}

\section{A Design of Model Matching Control Systems Based on Left Fraction Description of Transfer Function Matrix}

\section{Wataru KASE*}

\begin{abstract}
In the design of model matching control systems based on left fraction descriptions of a given transfer function matrix, some dynamics are added to solve the design equations. This note presents a design procedure which need not such an additional dynamics. Division algorithm of polynomial matrices given by Wolovich is extended for this.
\end{abstract}

Key Words : linear multivariable systems, matrix-fraction descriptions, model matching, division of polynomial matrices

\section{1. まえがき}

伝達行列の左分解表現に基づくモデルマッチング系の 構成は, 間接法タイプの適応制御系を構成する上で重要 である．このようなモデルマッチング系を構成する際, 多項式行列のある種の右からの割算が必要である ${ }^{1,2}$. 多 項式行列の右からの割算は，左分解表現の分母多項式行 列 $\tilde{P}(s)$ が列プロパーである場合には定義できるが, 一 般に $\tilde{P}(s)$ は列プロパーではない. そこで, 文献 1), 2)で は $D(s) \widetilde{P}(s)$ が列プロパーとなるように制御対象の分母 子に適当なダイナミクス $D(s)$ を付加して設計方程式が 解かれる。このようにして設計した場合, 当然得られる 補償器の次数も高くなるため好ましくない.

本稿では, 文献 3)で提案されている多項式行列の割算 アルゴリズムを再検討し, 分母多項式行列 $\tilde{P}(s)$ が行プ ロパーの場合でも適用できる形に拡張する。この方法は, $\tilde{P}(s)$ が列プロパーな場合は，右割算の商と㮃余を与え る、そして，これを用いて余分なダイナミクスを付加す る必要のない左分解表現に基づくモデルマッチング系の 一構成法を示す.

\section{2. 問題の設定と設計方程式の導出}

次式で与えられる制御対象を考える。

$$
y(s)=T(s) u(s)=R(s) P^{-1}(s) u(s)
$$

\footnotetext{
* 静岡理工科大学理工学部 袋井市豊沢 2200-2

* Faculty of Science and Technology, Shizuoka Institute of Science and Technology, Fukuroi

(Received July 8, 1992)

(Revised October 29, 1992)
}

$$
=\tilde{P}^{-1}(s) \tilde{R}(s) u(s)
$$

ここで, $u(s), y(s)$ は制御対象の入出力で共に $p$ 次元, $T(s)$ は制御対象の伝達関数行列で厳密にプロパー, 正 則とする。また， $P(s), \tilde{P}^{T}(s)$ は列プロパーであるとす る.

制御目的は， $T(s)$ を同じサイズの希望する安定な伝 達行列 $T_{m}(s)$ に漸近的に一致させるような一様有界入 力を発生させることである。このために以下の仮定が必 要である.

A1) $T(s)$ は最小位相系 $(\operatorname{det} R(s), \operatorname{det} \tilde{R}(s)$ は漸近安 定多項式)

\section{A2) $\xi(s) T_{m}(s)$ はプロパー，ただし， $\xi(s)$ は} $\lim _{s \rightarrow \infty} \xi(s) T(s)=G$ (nonsingular)

を満たす漸近安定多項式行列である。ここで，制御対象 の既約性に関する仮定は，仮定 A 1)があるため必要な い.

モデルマッチング補償器は, 以下の Diophantine 方程 式を解くことで得られることが知られている ${ }^{11}$.

$$
\begin{aligned}
& K(s) P(s)+H(s) R(s) \\
& \quad=Q(s)\left[P(s)-G^{-1} \xi(s) R(s)\right]
\end{aligned}
$$

ここで, $Q(s)$ は制御対象の可観測指数の最大值 $\nu$ に対 して, その行次数が $\nu-1$ 次の行プロパー漸近安定行列 である。（2)式は (1) 式を用いると以下のように変形て きる。

$$
\begin{aligned}
& {\left[H(s)+Q(s) G^{-1} \xi(s)\right]^{-1}[Q(s)-K(s)]} \\
& \quad=\tilde{P}^{-1}(s) \tilde{R}(s)
\end{aligned}
$$

$\xi(s)$ の最大次数を $d$ とすると, 上式より高々 $d-1$ 次の 多項式行列 $L(s)$ が存在して 


$$
Q(s) G^{-1} \xi(s)=L(s) \tilde{P}(s)-H(s)
$$

$$
L(s) \tilde{R}(s)=Q(s)-K(s)
$$

を満たすことがわかる.ここで, $\tilde{P}(s)$ は行プロパーなの で,一般に $H(s) \tilde{P}^{-1}(s)$ がプロパーとはならず, したがっ て多項式行列の Division Algorithmに類した手法で (4)式を解くことができないわけである.

\section{Division Algorithm の拡張}

$s$ を微分演算子, ラプラス演算子を共に表わすものと し, 制御対象の初期状態を 0 と仮定する. $\tilde{P}(s)$ は行プロ パーだから, $\tilde{P}^{-1}(s)$ の可観測正準実現 $\left(A_{0}, B_{0}, C_{0}\right)$ を 容易に得ることができる。この実現を用いた $z(s)$ $=\tilde{P}^{-1}(s) u(s)$ の状態方程式

$$
\begin{aligned}
& s x(s)=A_{0} x(s)+B_{0} u(s) \\
& z(s)=C_{0} x(s)
\end{aligned}
$$

において，任意の $f \geq 0$ に対して

$$
\begin{aligned}
S_{I}^{f}(s) z(s)= & \mathcal{O}_{f} x(s) \\
& +\boldsymbol{T}_{f-1} S_{I}^{f-1}(s) \tilde{P}(s) z(s)
\end{aligned}
$$

が成立する.ここで,

$$
S_{I}^{f}(s)=\left[\begin{array}{llll}
I & s I & \cdots & s^{f} I
\end{array}\right]^{T}
$$$$
\mathcal{O}_{f}=\left[\begin{array}{c}
C_{0} \\
C_{0} A_{0} \\
\vdots \\
C_{0} A_{0}^{f}
\end{array}\right]
$$

$$
\boldsymbol{T}_{f-1}=\left[\begin{array}{cccc}
0 & 0 & \cdots & 0 \\
C_{0} B_{0} & 0 & \cdots & 0 \\
C_{0} A_{0} B_{0} & C_{0} B_{0} & \cdots & 0 \\
\vdots & \vdots & \ddots & \vdots \\
C_{0} A_{0}^{f-1} B_{0} & C_{0} A_{0}^{f-2} B_{0} & \cdots & C_{0} B_{0}
\end{array}\right]
$$

である。

(6)式において, $f=\nu-1$ のときを考えて, $\widehat{O}_{\nu-1} を \widehat{O}_{\nu-1}$ から線形独立行を抜き出した行列， $W$ を

$$
W \widehat{O}_{\nu-1}=\widehat{O}_{\nu-1}
$$

\section{と定義すると}

$$
x(s)=\widehat{O}_{\nu-1}^{-1} W\left[S_{I}^{\nu-1}(s)-\boldsymbol{T}_{\nu-2} S_{I}^{\nu-2}(s) \tilde{P}(s)\right] z(s)
$$

が成立するから，(6)式に(9)式を代入して $z(s)$ を消去 すると

$$
\begin{aligned}
S_{I}^{f}(s)= & \mathcal{O}_{f} \widehat{\mathcal{O}}_{\nu-1}^{-1} W S_{I}^{\nu-1}(s) \\
& +\left[\boldsymbol{T}_{f-1}-\mathcal{O}_{f} \hat{\mathcal{O}}_{\nu-1}^{-1} W \boldsymbol{T}^{*}\right] S_{I}^{f-1}(s) \tilde{P}(s)
\end{aligned}
$$

ここで, $\boldsymbol{T}^{*}$ は, $\boldsymbol{T}_{\nu-2}$ を $S_{I}^{f-1}(s)$ のサイズに合せるため に適当に零列を挿入した行列である. $f$ を $N(s)$ $=Q(s) G^{-1} \xi(s)$ の次数として

$$
N(s)=N S_{I}^{f}(s)
$$

とすると,

$$
N(s)=N \mathcal{O}_{f} \hat{O}_{\nu-1}^{-1} W S_{I}^{\nu-1}(s)
$$

$$
+\boldsymbol{N}\left[\boldsymbol{T}_{f-1}-\widehat{O}_{f} \widehat{\mathcal{O}}_{\nu-1}^{-1} W \boldsymbol{T}^{*}\right] S_{I}^{f-1}(s) \tilde{P}(s)
$$

が得られる.ここで,

$$
\begin{aligned}
& L(s)=\boldsymbol{N}\left[\boldsymbol{T}_{f-1}-\mathcal{O}_{f} \widehat{\mathcal{O}}_{\nu-1}^{-1} W \boldsymbol{T}^{*}\right] S_{I}^{f-1}(s) \\
& H(s)=-\boldsymbol{N} \mathcal{O}_{f} \widehat{\mathcal{O}}_{\nu-1}^{-1} W S_{I}^{\nu-1}(s)
\end{aligned}
$$

とする.

（注意） モデルマッチング問題を考える上では, $\tilde{P}(s)$ の列プロパー性を仮定することは一般にはできない。し かし，上記の計算法自体は $\tilde{P}(s)$ が列プロパーでも (4) 式の多項式行列方程式の求解に利用することができる. しかもこの場合には, 文献 3) の結果を含む,つまり $L(s)$, $-H(s)$ は $N(s)$ を $\tilde{P}(s)$ で右から割ったときの商と剩余 に一致する.いま $\tilde{P}(s)$ の $i$ 番目の行次数を $\mu_{i}(i=1, \cdots$, p) とする. $\tilde{P}(s)$ は列プロパーであるので, $\tilde{P}^{-1}(s)$ の可制 御正準実現 $\left(A_{c}, B_{c}, C_{c}\right)$ を容易に得ることができる。こ の実現を用いて，(5)，（7)式を定義し，上述の計算を 行う。ここで, 行交換行列 $\hat{W} を$

$$
\widehat{W} \widehat{O}=\left[\begin{array}{c}
c_{c 1} \\
c_{c 1} A_{c} \\
\vdots \\
c_{c 1} A_{c}^{\mu_{1-1}} \\
\vdots \\
c_{c p} A_{c}^{\mu_{p-1}}
\end{array}\right]=I
$$

とすると, $W$ は $\widehat{W}$ の列に可制御指数個ごとに適当に零 列を挿入した行列であり， $\mu_{i} \leq \nu$ のき

$$
W S_{I}^{\nu-1}(s)=\text { block } \operatorname{diag}\left\{1, s, \cdots, s^{\mu_{i}-1}\right\}^{T}
$$

が成立し, 文献 3$)$ と同じ結果が得られる.また， $\mu_{i}>\nu$ な る $i$ が存在するときは

$$
\partial_{c i}\left[S_{I}^{\nu-1}(s)\right]=\nu-1 \leq \mu_{i}=\partial_{c i}[\tilde{P}(s)]
$$

なので, 商と剰余の一意性から文献 3) の結果と一致す る.ここで, $\partial_{c i}[P(s)]$ は $P(s)$ の $i$ 番目の列次数を表わ す.

\section{4. モデルマッチング系の構成}

(13)式に示すように(4)式を計算して得られる $K(s)$, $H(s)$ を用いて，モデルマッチング制御入力を次式のよ うに定義する.

$$
\begin{aligned}
u(s)= & Q^{-1}(s) K(s) u(s)+Q^{-1}(s) H(s) y(s) \\
& +G^{-1} \xi(s) T_{m}(s) v(s)
\end{aligned}
$$

ただし， $v(s)$ は外部基準入力である.

《定理》（17）式で示す制御入力は実現可能で，これを 用いることにより漸近的に $T(s)=T_{m}(s)$ が達成できる.

(証明) $\xi(s) T(s)$ は仮定より, $Q^{-1}(s) H(s)$ は前章の 議論よりプロパーである. $\tilde{P}(s) y(s)=\tilde{R}(s) u(s)$ の両辺 に左から $L(s)$ を乗じて，(4)式を用いて整理すると,

$$
\xi(s) y(s)=G u(s)-G Q^{-1}(s)[K(s) u(s)+H(s) y(s)]
$$

(1)式から 
$\xi(s) T(s)=G-G Q^{-1}(s)[K(s)+H(s) T(s)]$ 上式で $s \rightarrow \infty$ 考えることにより, $Q^{-1}(s) K(s)$ が厳密に プロパーであることがわかる。したがって，(17)式は実 現可能である.

制御目的の達成は, 2 章の導出から文献 1) と同様なの で省略する。

\section{5. あとがき}

本稿では, 余分なダイナミクスの導入を必要としない 伝達行列の左分解に基づくモデルマッチング系の構成法
を示した。この目的のために, 多項式行列の割算を含む， 多項式行列方程式の解法を示した。

\section{参 考 文 献}

1) H. Elliott and W. A. Wolovich: Parameterization Issues in Multivariable Adaptive Control, Automatica, 20-5, 533/545 (1984)

2) G. C. Goodwin and K. S. Sin : Adaptive Filtering, Prediction and Control, Prentice-Hall (1984)

3) W. A. Wolovich: Division Algorithm for Polynomial Matrices, IEEE Transactions on Automatic Control, AC-29-7, 656/658 (1984) 